\title{
Bacterial Isolates and their Antibiotic Susceptibility Pattern among Patients with Pus and/or Wound discharge at Gouri Devi Institute of Medical Sciences and Hospital
}

\author{
R. Priscilla* and Arun Ghosh \\ Department of Microbiology, Gouri Devi Institute of Medical Sciences and Hospital, \\ Durgapur, West Bengal, India \\ *Corresponding author
}

\section{A B S T R A C T}

In spite of advances in control of infections, wound infections have not completely controlled due to many reasons. The widespread uses of antibiotics, together with the length of time over which they have been available have led to major problems of resistant organisms contributing to morbidity and mortality. This study was aimed to assess bacterial isolates and their drug susceptibility patterns from patients with pus and/or

\section{Keywords}

Pus, Wound discharge, Surgical site infection (SSI) and Pseudomonas aeruginosa

Article Info

Accepted:

26 April 2019

Available Online:

10 May 2019 wound discharge. A retrospective study was conducted at Gouri Devi Institute of Medical Sciences and hospital from all individuals who provide pus and/or wound discharge samples from June 2017 to May 2018. The records of wound swab samples obtained from patients with different kinds of wounds, receiving treatment at the Gouri Devi Institute of Medical Sciences and Hospital, Durgapur, West Bengal, were analysed by using a standard data collection format. Data were analyzed using SPSS version 11 software. P-value $\leq 0.05$ was considered statistically significant. A total of 104 samples were included in the study with bacterial isolation rate of 87 with the isolation rate of $(83.65 \%)$. Of all, $56(53.84 \%)$ were females, $75(86.20 \%)$ of the isolates were gram negative and $12(13.79 \%)$ were gram positive. About 39/87 (44.82\%) of the total isolates were Pseudomonas aeruginosa, Coagulase positive Staphylococci (13.79\%), Coliform (except E. coli) (13.79\%), Proteus mirabilis (11.49\%), Klebsiella pneumoniae (9.19\%) and Escherichia coli (6.89\%). The result showed that $66.2 \%$ of the isolates were resistant to tetracycline, followed $59.8 \%$ for ampicillin, $59.1 \%$ for cotrimoxazole, $51.7 \%$ for Erythromycin, least resistant being $6.3 \%$ for gentamycin. High prevalence of bacterial isolates were found; Pseudomonas aeruginosa being the dominant. Most of the isolates were resistant to many of the antibiotics tested where all isolates of Staphylococcus aureus being resistant to two or more antibiotics. Antibiotic susceptibility test is necessary for effective control of wound infections.

\section{Introduction}

A wound is a breakdown in the protective function of the skin; the loss of continuity of epithelium, with or without loss of underlying connective tissue ${ }^{1}$. Wounds can be accidental, pathological or post-operative. An infection of this breach in continuity constitutes wound 
infection. Wound infection is thus the presence of pus in a lesion as well as the general or local features of sepsis such as pyrexia, pain and induration. Infectious diseases still remain an important cause of morbidity and mortality among humans, especially in developing countries. Various species of bacteria live on human skin, gastrointestinal tract, in the nasopharynx and other parts of the body with less potential for causing disease because of first line defense within the body. Skin abrasion due to surgical procedure, trauma, burns, diseases, nutrition and other factors affect this first line defense and leads to microbial contamination results infections ${ }^{1}$. As wound infections are largely hospital acquired and the infecting pathogens not only differ from country to country, but also vary from one hospital to another within the same country ${ }^{2}$.

The problem of hospital acquired infection remains a serious health hazard worldwide. As described by World Health Organization $(\mathrm{WHO})^{3}$, it is one of the major sources of infectious diseases which results for the huge economic impact with significant rate of morbidity and mortality. Studies on wound infection have largely focused on surgical site infections ${ }^{6}$. This might be because other types of wound infection are not problematic in the developed world where most of these studies have been done. Despite advances in control of infections, wound infections have not completely prevented due to the problem of drug resistance ${ }^{4}$. The widespread uses of antibiotics, together with the length of time over which they have been available, have led to major problems of resistant organisms contributing to morbidity and mortality ${ }^{5}$. Knowledge of the causative agents of wound infection has proven to be helpful in the selection of appropriate antimicrobial therapy and on infection control measures taken in health institutions ${ }^{6}$. Therefore, the present study aimed to evaluate the important causative agents of bacteria and their antibiotic susceptibility pattern which may be imperative as it guides the selection of an effective regimen for the treatment.

\section{Materials and Methods}

\section{Study design}

This was a retrospective cross-sectional study spanning 12 months from June 2017 to May 2018. The records of wound swab samples obtained from patients with different kinds of wounds, receiving treatment at the Gouri Devi Institute of Medical Sciences and hospital, Durgapur, West Bengal, were analysed.

\section{Study area}

The Gouri Devi Institute of Medical Sciences and hospital, is a teaching hospital that provides health services to many inhabitants of Durgapur, West Bengal State, as well as patients from the neighbouring Delta State and Rivers State. The majority of inhabitants are farmers, fishermen and civil servants.

\section{Exclusion/inclusion criteria}

The records were scrutinized in such a way that all patients with suspected wound infections were added to the study. Wound infection was suspected if a wound was not healing well, getting bigger, exuding pus or fluid. Very ill patients and those undergoing antibiotic therapy two weeks prior to the study were excluded. Patients' age, sex and type of wound were noted.

\section{Sample collection}

Wound swabs and discharges were aseptically collected using sterile swab in a test tube. The samples were transported to the microbiology department within one hour of collection to prevent drying of the swabs, and Swabs were 
immediately inoculated on to Chocolate agar, Blood agar, MacConkey agar and Cystine lactose electrolyte-deficient agar (CLED). Plates were incubated at $37^{\circ} \mathrm{C}$ for $24-48$ hours. Once pure colonies identified series of biochemical tests were performed for the isolation of the species following standard procedures ${ }^{7}$.

\section{Antimicrobial susceptibility tests}

Antimicrobial susceptibility testing was performed by using Muller-Hinton agar, Kirby-Bauer disc diffusion method, and interpreted according to the recommendations of the Clinical Laboratory Standards Institute

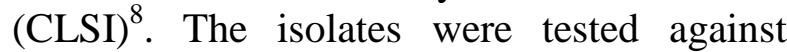
Chloramphenicol $(30 \mu \mathrm{g})$, Ampicillin $(10 \mu \mathrm{g})$, Ciprofloxacin $(5 \mu \mathrm{g})$, Gentamicin $(10 \mu \mathrm{g})$, Co-trimoxazole $(5 \mu \mathrm{g})$, Tetracycline $(30 \mu \mathrm{g})$, Nalidixic acid $(30 \mu \mathrm{g})$, Ceftriaxone $(30 \mu \mathrm{g})$, Norfloxacin $(30 \mu \mathrm{g})$. For gram-positive isolates, Erythromycin $(15 \mu \mathrm{g})$, Methicillin (5 $\mu \mathrm{g})$, Vancomycin, $(30 \mu \mathrm{g})$, Streptomycin (10 $\mu \mathrm{g})$ were included. Plates were incubated at $35-37^{\circ} \mathrm{C}$ for $16-18$ hours. The zones of inhibition were measured and compared with the guidelines ${ }^{8}$.

\section{Results and Discussion}

A total of 104 wound swab samples received at the Microbiology Department, Gouri Devi Institute of Medical Sciences and hospital, Durgapur, West Bengal, over a 12 month period (June 2017 to May 2018) were analysed. There were 48 male subjects and 56 female subjects, ages ranged from two months to 65 years, with a mean of 35 years (Table $1)$.

A total of 87 samples $(83.65 \%)$ yielded significant bacterial growth indicative of wound infection, while 17 samples did not yield significant growth. No sample yielded more than one organism.

\section{Type of wound}

Non-traumatic causes (including diabetic foot ulcers) accounted for more than a third of all infected wounds (Table 2). There was no association between the type of wound and the type of micro-organism isolated. All swabs obtained from patients with Nontraumatic wounds yielded bacterial growth, and the majority of these patients were females $(65.62 \%)$.

\section{Age}

There was greater incidence of wound infection in the 21 - 30 year age group, but there was no significant association between age and the incidence of wound infection.

\section{Sex}

There was no significant association between the type of organism isolated and the sex of the subject or between the wound type and the sex of the subject.

\section{Micro-organisms isolated}

Gram-negative bacilli were the most prevalent bacteria isolated from the wound swabs (86.20\%). Pseudomonas aeruginosa was the most prevalent pathogen detected in the swabs, while Escherichia coli was the least detected isolate. Gram negative bacilli were responsible for $86.20 \%$ of wound infections. Staphylococcus aureus was the only gram positive organism isolated. Pseudomonas aeruginosa was the predominant microorganism isolated from the wound swabs, accounting for almost half of the isolates (Table 3). No particular organism was peculiar to any of the wound types (Table 4).

Bacterial contamination of wounds is a serious problem in the hospital, especially in surgical practice where the site of a sterile 
operation can become contaminated and subsequently infected ${ }^{16,17}$. Among 104 study subjects, bacterial pathogens were isolated from 87 patients with the isolation rate of $83.65 \%$. This was higher than the results reported by Mulu et al., 9 . This variation may be due to little variation in laboratory facilities that we have currently. Among the total isolates, $(86.20 \%)$ were gram negative and Staphylococcus aureus was the only gram positive organism isolated.

The predominant isolates in the present study was found to be Pseudomonas aeruginosa, which was $44.82 \%$, this was consistent with reports from India $30.1 \%$ and lower than Gondar hospital $65 \%{ }^{9,10}$. Although, S. aureus is predominant in both reports, the rate of isolation declined compared to the previous reports which was $65 \% 9$. This low rate of isolation may be due to improved facilities of the hospital management at present in the infection control program. Although there was no association between the type of wound and the type of micro-organism isolated, it is important to note that all swabs from Nontraumatic wounds yielded significant bacterial growth and were thus deemed to indicate infection. However, two previous studies also done in Nigeria had associated specific microorganisms with particular wound types 16,17 . More studies are required to clarify this observation. Most of these studies, including ours, are limited by the fact that anaerobic cultures were not done for a variety of reasons, the main one being a lack of equipment and funds. Thus, anaerobic bacteria, which are also important in wound infections, could not be isolated.

Most of the isolates were resistant to many of the antibiotics tested. The result showed that $66.2 \%$ of the isolates were resistant to tetracycline, followed $59.8 \%$ for ampicillin, $59.1 \%$ for cotrimoxazole, $51.7 \%$ for Erythromycin, least resistant being $6.3 \%$ for gentamycin. Among isolates tested, $18.3 \%$ of the isolates are becoming resistant to ceftriaxone and $33.3 \%$ for vancomycin. Among resistant isolates to more than one antibiotic, the most common pathogen was Pseudomonas spp., 100\%; followed by E. coli $83.4 \%$ of the isolates were sensitive to all drugs tested and 68 were resistance to only one drug. However, among the total isolates, $87(78.16 \%)$ were resistant for two or more drugs tested and $19(21.83 \%)$ were resistant to more than 5 antibiotics tested. This finding was supported by other studies done in Ethiopia ${ }^{11,12}$. The lack of diagnostic facilities in these developing regions encourages empiric treatment and overtreatment, which contribute to the increased resistance ${ }^{14}$.

Table.1 Age distribution of patients with significant bacterial growth

\begin{tabular}{|l|c|c|c|}
\hline Age group & Total no. of & \multicolumn{2}{|c|}{ No. of infected swabs } \\
\cline { 3 - 4 } & swabs & Males & Females \\
\hline $\mathbf{0}-\mathbf{1 0}$ & 12 & $\mathbf{7}$ & 4 \\
\hline $\mathbf{1 1}-\mathbf{2 0}$ & 14 & 4 & 8 \\
\hline $\mathbf{2 1}-\mathbf{3 0}$ & 34 & 15 & 17 \\
\hline $\mathbf{3 1}-\mathbf{4 0}$ & 19 & 5 & 6 \\
\hline $\mathbf{4 1}-\mathbf{5 0}$ & 11 & 3 & 5 \\
\hline $\mathbf{5 1}-\mathbf{6 0}$ & 14 & 7 & 6 \\
\hline Total & 104 & 41 & 46 \\
\hline
\end{tabular}


Table.2 Frequency of wound types

\begin{tabular}{|l|c|c|c|c|}
\hline Type of wound & No. of swabs & $\begin{array}{c}\text { No. of infected } \\
\text { swabs }\end{array}$ & \multicolumn{2}{|c|}{ Patients with Infected Wounds } \\
\cline { 4 - 5 } & & $27(31.03 \%)$ & 6 & Males \\
\hline Surgical & $32(30.76 \%)$ & $22(25.28 \%)$ & 21 & 21 \\
\hline Trauma & $23(22.11 \%)$ & $32(36.78 \%)$ & 11 & 21 \\
\hline Non-traumatic & $40(38.46 \%)$ & $6(06.89 \%)$ & 3 & 3 \\
\hline Burns & $9(08.65 \%)$ & 87 & 41 & 46 \\
\hline Total & 104 & & &
\end{tabular}

Table.3 Frequency of micro-organism isolated

\begin{tabular}{|l|c|c|}
\hline Micro-organism isolated & Male & Female \\
\hline Pseudomonas aeruginosa & 12 & 27 \\
\hline Staphylococcus aureus & 7 & 5 \\
\hline Coliform (except E. coli) & 8 & 4 \\
\hline Proteus mirabilis & 6 & 4 \\
\hline Klebsiella pneumoniae & 5 & 3 \\
\hline Escherichia coli & 3 & 3 \\
\hline Total & 41 & 46 \\
\hline
\end{tabular}

Table.4 Frequency of micro-organisms according to wound types

\begin{tabular}{|c|c|c|c|c|c|}
\hline \multirow[t]{2}{*}{ Micro-organism } & \multicolumn{4}{|c|}{ Type of wound } & \multirow[t]{2}{*}{ Total } \\
\hline & Surgical & Trauma & Non-traumatic & Burns & \\
\hline $\begin{array}{l}\text { Pseudomonas } \\
\text { aeruginosa }\end{array}$ & 7 & 9 & 19 & 4 & 39 \\
\hline Staphylococcus aureus & 2 & 8 & 2 & 0 & 12 \\
\hline Coliform (except E.coli) & 6 & 0 & 4 & 2 & 12 \\
\hline Proteus mirabilis & 3 & 2 & 5 & 0 & 10 \\
\hline Klebsiella pneumoniae & 5 & 2 & 1 & 0 & 8 \\
\hline Escherichia coli & 4 & 0 & 2 & 0 & 6 \\
\hline Total & 27 & 21 & 33 & 6 & 87 \\
\hline
\end{tabular}

The majority of the patients who were positive for wound culture were in the age range of 21 - 30 years, which was 34 $(32.69 \%)$, this was higher than the results reported by Mulu et al., ${ }^{9}$. followed by in the age range of 31- 40 years, which was 19 $(18.26 \%)$; age range of $11-20$ which was 14 (13.46\%). Among 104 isolates, 56 (53.84\%) were female and 48 (46.15\%) were male patients. These results demonstrate that being female is found a risk factor for getting an infection by bacteria. Females were found to be at risk to get infected by bacteria than males. When we compared the culture positivity of the samples, pus/discharge samples were 2.38 times positive for bacterial isolates than wound swab samples. As to the limitation of this study; since it is a retrospective study some of the data registered were not as to the standard and were not included. We also fail to include more variables because of unavailability. 
Ideally, the age of a patient seems likely to have a bearing on wound infection and healing, people at the extremes of life being more prone to wound infections. However, we observed no association between age and wound infection, a finding that is inconsistent with the results of a study done in the Niger Delta region $^{13}$ and another in Ethiopia ${ }^{14}$.

In conclusion, high prevalence of bacterial isolates was found from patients who provide pus and/or wound discharge sample in the study site Pseudomonas aeruginosa, being the dominant. Most of the isolates were resistant to many of the antibiotics tested where all isolates of $S$. aureus being resistant to two or more antibiotics. It is, therefore, necessary to do an antibiotic susceptibility test before drug prescription to effectively control wound infection. A rigorous infection control policy combined with rational drug use play an important role in this fight against antimicrobial resistance. We suggest the inclusion of anaerobic culture in routine microbiology culture investigations.

\section{References}

1. Leaper, DJ., Harding KG. Wounds: Biology and Management. Oxford, England: Oxford University Press; 1998.

2. Bowler, P., Duerden I, Armstrong D. Wound microbiology and associated approaches to wound management. Clin Microbiol Rev., 2001; 14(2): 244-269.

3. Alexander, FM., Wound Infection: Nursing Practice Hospital and Home, the Adult. New York: Churchill Livingstone; 1994.

4. Sule, A., Thanni L, Sule-Odu O, Olusanya O. Bacterial pathogens associated with infected wounds in Ogun state University Teaching Hospital, Sagamu, Nigeria. Afr J Clin Exp
Microbiol., 2002; 3(1): 13-16.

5. Dionigi, R., Rovera F, Dionigi G, Imperatori A, Ferrari A, Dionigi P, Dominioni L. Risk factors in surgery. J Chemother., 2001; Spec No 1(1): 611.

6. Sands, K., Vineyard G, Platt R. Surgical site infections occurring after hospital discharge. J Infect Dis., 1996; 173: 963-970.

7. Garner JS., CDC guideline for prevention of surgical wound infections, 1985. Supersedes guideline for prevention of surgical wound infections published in 1982. (Originally published in 1995). Revised. Infect Control 1986; 7(3): 193-200.

8. Gaynes, R., Culver D, Horan T, Edwards J, Richards C, Tolson J. Surgical Site Infection (SSI) Rates in the United States, 1992-1998: The National Nosocomial Infections Surveillance System Basic SSI Risk Index. Clin Infect Dis., 2001; 33(Suppl 2): S69S77.

9. Mehta, M., Dutta P, Gupta V. Bacterial isolates from burn wound infections and their antibiograms: A eight-year study. Indian J Plastic Surg., 2007; 40(1): 25-28.

10. Anguzu, JR., Olila D. Drug sensitivity patterns of bacterial isolates from septic post-operative wounds in a regional referral hospital in Uganda. Afr Health Sci., 2007; 7(3): 148-154

11. Fadeyi, A., Adigun I, Rahman G. Bacteriological pattern of wound swab isolates in patients with chronic leg ulcer. Int J Health Res 2008; 1(4): 183-188.

12. Wariso, B., Nwachukwu C. A survey of common pathogens in wounds in patients at the University of Port Harcourt Teaching Hospital (U.P.T.H), Port Harcourt. West Afr J Med., 2003; 22(1): 50-54. 
13. Egbe, C., Omoregie R, Igbarumah I, Onemu S. Microbiology of Wound Infections Among patients of a Tertiary Hospital in Benin City, Nigeria. J Res Health Sci., 2011; 11(2): 109-113.

14. Hart, C., Kariuki S. Antimicrobial resistance in developing countries. BMJ., 1998; 317: 647-650

15. Howard, RJ., Ravitch MM, Steichen FM: Host against Infections. Current Problems in Surgery. New Eng J
Med., 1980, 12: 1823-1830.

16. Taiwo, S., Okesina A, Onile B. In vitro antimicrobial susceptibility pattern of bacterial isolates from wound infections in University of Ilorin Teaching Hospital. Afr J Clin Exp Microbiol., 2002; 3(1): 6-10.

17. Mulugeta, KA., Bayeh A. Bacteriology and antibiogram of pathogens from wound infections at Dessie Laboratory, North East Ethiopia. Tanz J Health Res., 2011; 13(4).

\section{How to cite this article:}

Priscilla, R. and Arun Ghosh. 2019. Bacterial Isolates and their Antibiotic Susceptibility Pattern among Patients with Pus and/or Wound discharge at Gouri Devi Institute of Medical Sciences and Hospital. Int.J.Curr.Microbiol.App.Sci. 8(05): 2468-2474.

doi: https://doi.org/10.20546/ijcmas.2019.805.291 